\title{
Correction to: Inclusive Preschool Practitioners' Implementation of Naturalistic Developmental Behavioral Intervention Using Telehealth Training
}

\author{
Sophia D'Agostino ${ }^{1}$ [D $\cdot$ Sarah N. Douglas ${ }^{2}$ - Elizabeth Horton ${ }^{1}$
}

Published online: 1 February 2021

๑) Springer Science+Business Media, LLC, part of Springer Nature 2021

\section{Correction to:}

Journal of Autism and Developmental Disorders

(2020) 50:864-880

https://doi.org/10.1007/s10803-019-04319-z

The original version of the article has incorrect labels for Figs. 1 and 2.

The corrected versions of Figs. 1 and 2 are given below.

The original article can be found online at https://doi.org/10.1007/ s10803-019-04319-z.

Sophia D'Agostino

dagostino@hope.edu

Sarah N. Douglas

sdouglas@msu.edu

Elizabeth Horton

horton@hope.edu

1 Hope College, Van Zoeren Hall, 41 Graves Place, Holland, MI 49423, USA

2 Human Development and Family Studies, Michigan State University, 1C Human Ecology, East Lansing, MI 48824, USA 


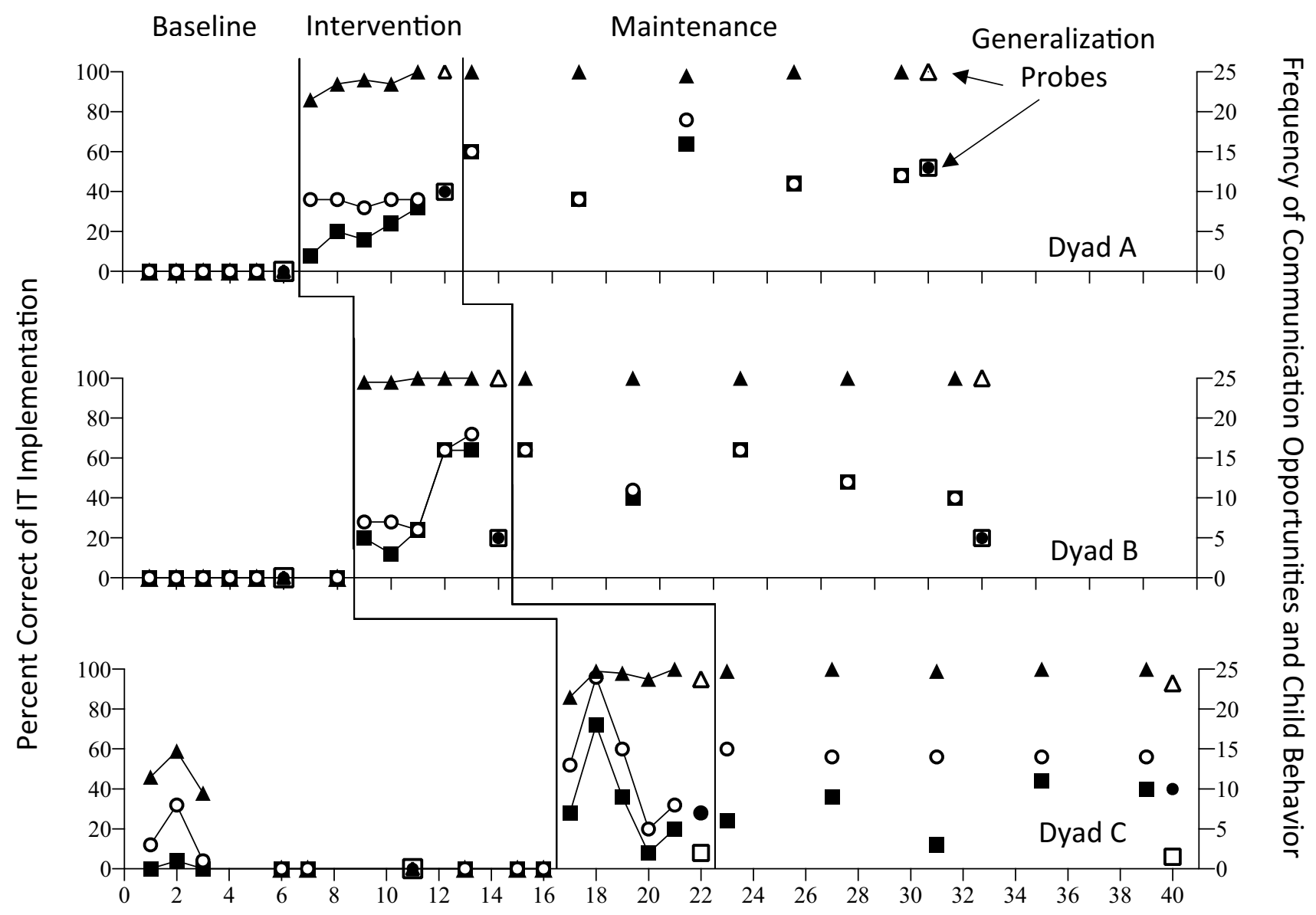

Sessions

Fig. 1 Practitioner IT implementation fidelity in closed triangles corresponding to left y-axis. Frequency of target communication opportunities provided in open circles and child target communication behavior in closed squares corresponding to the right y-axis. General- ization probes in open triangles for practitioner implementation fidelity, closed circles for communication opportunities, and open squares for child behavior. 


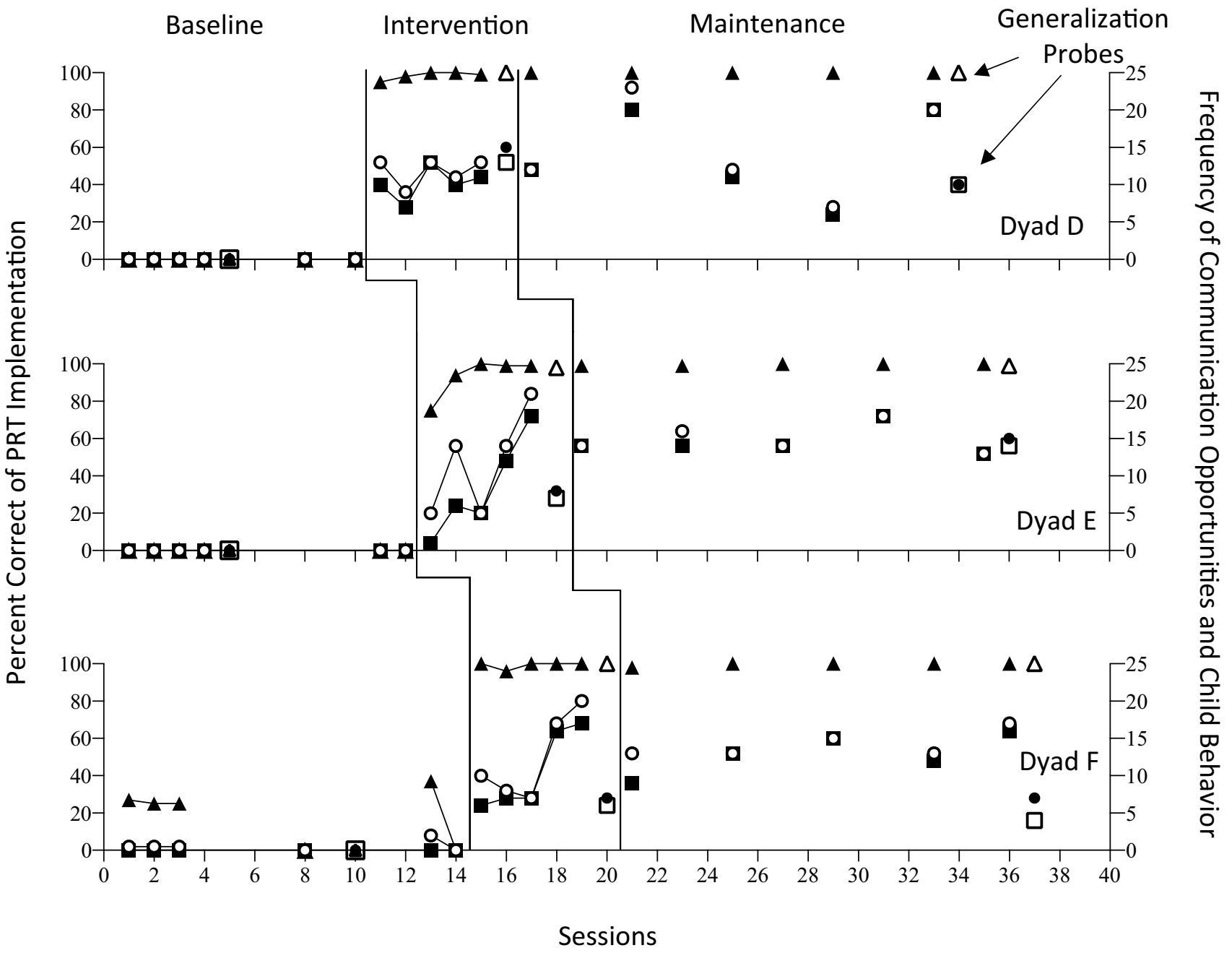

Fig. 2 Practitioner PRT implementation fidelity in closed triangles corresponding to left y-axis. Frequency of target communication opportunities provided in open circles and child target communication behavior in closed squares corresponding to the right $\mathrm{y}$-axis.
Generalization probes in open triangles for practitioner implementation fidelity, closed circles for communication opportunities, and open squares for child behavior.

Publisher's Note Springer Nature remains neutral with regard to jurisdictional claims in published maps and institutional affiliations. 